Удк 711.43-053.2

\title{
ПОДХОДЫ К ОРГАНИЗАЦИИ ПРОЕКТИРОВАНИЯ ГОРОДСКОЙ СРЕДЫ РАЗВИТИЯ: ГОРОД ДЛЯ ДЕТЕЙ
}

\author{
Зверев Алексей Игоревич, \\ zverefff@ya.ru \\ Алешина Елена Викторовна, \\ e-w-a-1@yandex.ru \\ Карачков Сергей Михайлович, \\ serkar@mail.ru \\ Россия, 620001, Екатеринбург, ул. 8 Марта, 66
}

Уральский институт управления Российской академии народного хозяйства и государственной службы при Президенте Российской Федерации,

Зверев Алексей Игоревич, кандидат социологических наук, докторант кафедры теории и социологии управления Уральского института управления Российской академии народного хозяйства и государственной службы при Президенте Российской Федерации.

Алешина Елена Викторовна, соискатель кафедры теории и социологии управления Уральского института управления Российской академии народного хозяйства и государственной службы при Президенте Российской Федерации.

Карачков Сергей Михайлович, кандидат социологических наук, докторант кафедры теории и социологии управления Уральского института управления Российской академии народного хозяйства и государственной службы при Президенте Российской Федерации.

\begin{abstract}
Актуальность заключается в постановке проблемы анализа роли детей в проектировании ориентированной на них городской среды, в которой они развиваются и растут. Цель - исследование методов включения детей в процесс принятия решений по вопросам городского проектирования (как полноценных участников), в ходе которого формируется активная городская среда развития. Объектом выступает городская среда как совокупность условий жизнедеятельности детей. В качестве предметной области избрана возможность применения концепции и методологии партисипативного проектирования при формировании городской среды, дружественной детям. Выводы основаны на анализе ситуации вокруг создания городов, доброжелательных к ребенку, а также различных последствий, связанных с подчеркиванием значения интеграции, институционализации и инноваций. Интеграция подразумевает вовлечение детей в разработку проектов, ориентированных на них; институционализация - необходимость создания соответствующих структур и учреждений, которые удовлетворяют потребности детей на практике; инновация предполагает новые способы включения детей в сценарии городского развития как полноправных участников гражданских процессов. Другими словами, должна быть интеграция идей, действий и знаний, а также институционализация позитивного социального опыта и инновация эффективных способов удовлетворения потребностей ребенка. Авторы также пришли к заключению о том, что основная проблема среды современных городов заключается в ее недружелюбности по отношению к потребностям детского развития, низком образовательно-воспитательном потенциале, поскольку среда существенно ограничивает возможности активной деятельности детей.
\end{abstract}

Ключевые слова: Проектирование, партисипация, социальный актор, образовательно-воспитательный потенциал, дружественные к детям городские пространства. 


\section{Актуальность проблемы исследования}

В современном обществе дети составляют значительную долю городского населения. Они формируют важную часть городской жизни, взаимодействуют и развиваются в городской среде. Дети - основные пользователи социальных услуг школ и парков, игровых и рекреационных зон. Однако взрослые формируют культуру и среду этих мест (как совокупность условий) независимо от детей, их мнение не берется в расчет, не учитывается даже в малой мере при городском проектировании. Фактически дети исключены из процесса принятия решений, которые между тем определяют их среду обитания, места, которые они посещают и используют ежедневно. Взрослые также всецело контролируют использование этих мест детьми. Очевидно, это создает разрыв между эффективностью и результатами, ожидаемыми при проектировании городской среды для детей и той реальной ситуацией, которая имеет место в большинстве случаев. По мнению авторов данной статьи, проектирование городской среды должно осуществляться с учетом интересов и потребностей детей. Сложность реализации данного требования заключается в том, что дети в современном обществе не являются полноправными участниками общественных отношений. Это зафиксировано как в нормативно-правовом поле (ограничение дееспособности, правоспособности и пр.), так и нормативно-ценностном (традиции, обычаи, культура). По мнению авторов, учитывать мнения детей в выработке решений по формированию городской среды важно и возможно в ходе организации её партисипативного проектирования (от англ. participation - вовлечение, со-участие).

\section{Теоретико-методологическая разработанность проблемы}

В современной литературе вопросы социального, партисипативного проектирования отражены в работах целого ряда отечественных и зарубежных авторов (R. Akoff [1], S.R. Amstein [2], M.T. Dang, A. Amos, M. Dangerfield, B. Ford, K. Kern [3], C. Dayer [4], O.B. Мороз [5], Л.С. Сафонова [6], Е.М. Шумкин [7] и др.). Вопросы партисипативного проектирования рассматриваются в основном с точки зрения организационного управления (корпоративная партисипативность), муниципального управления (организация населения в решении вопросов местного значения), социологии (партисипация в решении вопросов инклюзивного участия, партисипаторные эмпирические исследования бедности, расселения трущоб), градостроительства (привлечение активных групп горожан к проектированию городского развития). Отдельные аспекты реализации принципа партисипативности в различных социальных сферах взаимоотношений анализируют Е.А. Казаева (оценка роли партисипативности в системе высшего образования) [8], И.Ш. Пясецкая (понятийно-терминологический аппарат исследования проблемы формирования партисипативной культуры) [9], Н.Ю. Корнеева, М.В. Кожевников, Н.В. Уварина (анализ демократических «партисипативных» форм соучастия в управлении организациями и различными социальными общностями) [10].

\section{Понятие и методология партисипации и партисипативного проектирования среды}

В научной литературе термин «партисипация» соотносится главным образом с категориями «участие», «соучастие», «вовлеченность» (см. работы таких авторов, как У.Д. Дункан, У.И. Деминг, О. Ирвин, П.Б. Петерсон и др.). Например, как отмечает К. Дэйер, «под партисипацией в строгом смысле слова следует понимать вовлечение людей в управленческую деятельность существующих организаций, как формальных, так и неформальных» [4]. В общем смысле, по мнению А.А. Деникина, «привлечение подходов, ориентированных на нужды и интересы людей, означает, что человек сам становится от- 
ветственен за своё будущее, увеличивается роль “социального капитала"» [11, с. 62]. Таким образом, партисипация характеризует такое взаимодействие между людьми, когда каждый человек, проявляя активность, дополняет результаты, полученные в процессе взаимного обмена информацией.

Так, по мнению Н.С. Шкитиной, «партисипация функционирует в социальных общностях, где присутствуют субъект-субъектные отношения, она предполагает установление сотрудничества, расширения прав в принятии решений, расширение возможностей самоуправления» [12, с. 53]. Логично, что ряд исследователей соотносит понятие «партисипации» с понятием «самоуправление». К примеру, С. Хилли выделяет управленческий аспект городской коммуникации, который играет первостепенную роль в обмене информацией субъектов управления [13]. Рассматривая управленческую функцию городской коммуникации, автор вплотную подходит к таким понятиям, как «самоуправление» и «со-управление».

В культурологическом дискурсе партисипация также понимается как «культура участия или соучастия», предполагает определенное приближение человека, который ранее был только потребителем культурных и социальных смыслов, к позиции производителя, инициатора.

Применительно к социологии города партисипацию и партисипативность можно рассматривать как альтернативу распространенному на практике муниципального управления принципу авторитарности (внешнего управления), метода организации городских коллективов и формирования профессиональной подготовки специалистов социальной сферы, значительно расширяющего потенциал управления, способствующего формированию отношений взаимной ответственности, сотрудничества, инициативности, самостоятельности, самоуправления. Здесь, в том числе, можно говорить о возможности сбора и кристаллизации мнений детей с последующей выработкой на их основе значимой управленческой информации в сфере городского управления.

Что касается непосредственно применения принципа партисипации к социальному проектированию городской среды, то можно отметить, что на практике различных социальных общностей партисипативное проектирование обеспечивает прямую вовлеченность в проектирование всех тех, кого оно непосредственно затрагивает (Д. Нджеру [14], Ф. Бараса и Дж. Тьюбей [15] и др.).

Таким образом, на уровне теоретико-методологического обобщения специфика партисипативного проектирования заключается в следующем: субъект проектирования (инициатор) формирует совокупность условий для вовлечения заинтересованных лиц - представителей основных (возможных) групповых акторов - в процесс групповой выработки целевых образов социальной общности в будущем (конечных целей), а также совокупности средств (промежуточных целей) и создания соответствующих партисипативных проектов (сложных целевых образов). Инициатор вырабатывает проект партисипативной среды (совокупности условий) в организации и формализует, детализирует его в рамках соответствующего плана, предполагающего также четкую программу реализации задуманного сложного целевого образа среды. Отличительной чертой партисипативного проектирования в данном случае будет являться выработка таких решений, которые расширяют круг возможностей для вовлеченных инициатором (инициаторами) субъектов проектирования из числа заинтересованных лиц (в том числе детей - в нашем случае). Таким образом, в рамках методологического партисипативно-проектного подхода достигается результативность возможных способов коллективной выработки образа организации лицами, которые в этом потенциально заинтересованы, сочетания внешнего управления и самоуправления [16]. 


\section{Концепция «child friendly city» и возможности учета мнений детей в проектировании городской среды}

Здесь речь идет главным образом о том, что принципиальные различия между потребностями, предпочтениями и поведением детей и взрослых должны приниматься во внимание в каждом целевом аспекте городского проектирования.

В «вовлеченной», открытой, прозрачной и отзывчивой системе управления всем гражданам уделяется должное внимание, независимо от возраста, этнического происхождения, дохода, пола или особенностей социального статуса. Дети находятся под влиянием среды обитания и способны на нее влиять. Концепция городов, доброжелательных к ребенку должна быть разработана для обеспечения того, чтобы городские власти последовательно принимали решения в интересах детей и города формировали дружелюбную для детей городскую среду, ориентированную на здоровье, заботу, защиту, образование, стимулирование, отсутствие дискриминации, инклюзивность, культурную насыщенность и т. д.

Концепция «child friendly city», т. е. города с наличием социальной среды, доброжелательной к ребенку, была впервые выдвинута в 1996 г. в качестве инициативы по выполнению резолюции, принятой во время второй конференции ООН по населенным пунктам (Хабитат II) [17], чтобы сделать города пригодными для жизни.

Конференция ООН в частности провозгласила:

- благополучие детей является главным индикатором «здоровой среды обитания», демократического общества и результативного муниципального управления;

- необходимо учитывать потребности детей и молодежи, особенно в отношении их среды обитания;

- важно понимать необходимость включения детей в общественные процессы, связанные с формированием городов, поселков и кварталов и т. д.;

- необходимо результативно использовать в городском проектировании видение детей и молодежи, а также их творческий подход и свежие мысли об окружающей (городской) среде и пр.

Подобные идеи, отраженные в декларации, подкреплены на сегодняшний день Конвенцией о правах ребенка, принятой Генассамблеей ООН в 1989 г. [18]. Конвенция включает в себя ряд разделов, непосредственно касающихся участия детей в городском проектировании, например таких, как раздел 12 о праве детей свободно выражать свое мнение по вопросам, которые их касаются. На сегодняшний день содействие участию детей и молодежи в принятии решений городского самоуправления, а также в качестве активных участников повседневной семейной и общественной жизни (с учетом возрастных ограничений и особенностей) должно стать важной частью политических и программных инициатив органов государственной власти и местного самоуправления, представителей общественных организаций и т. д.

\section{Дискуссия и авторская позиция по проблеме}

Обозначим пять базовых принципов, которые должны использоваться управляющими субъектами и имеют важное значение, если ставится цель вовлечения детей и молодежи в реальные процессы со-участия в организации, реализации и оценке результатов городского проектирования:

- признание важной роли участия детей в проектировании;

- обеспечение правовой основы такого участия на уровне муниципалитета;

- наличие результативного координационного механизма; 
- наличие соответствующего «детского» бюджета;

- мониторинг (анализ и оценка) воздействия на детей, регулярный отчет «Состояние детей города».

Согласно общей позиции ЮНИСЕФ, город, доброжелательный к ребенку, нуждается в базовых элементах, обеспечивающих его способность выполнять принципы Конвенции о правах ребенка. Цель состоит в том, чтобы улучшить жизнь детей путем признания и реализации на практике их потребностей. Создание города, доброжелательного к ребенку, - это практический, а не теоретический процесс, который должен активно взаимодействовать с детьми и их реальной жизнью.

Согласно ЮНИСЕФ дружелюбным в отношении детей можно назвать тот город, в котором:

- муниципалитет реализует политику, включая распределение ресурсов и использование технологий управления, отвечающую интересам не только взрослого населения, но и детей;

- созданы условия, способствующие безопасности, открывающие необходимые и достаточные возможности для отдыха, социального взаимодействия, психологического развития и культурного самовыражения детей и молодежи;

- д дети имеют право участвовать в принятии решений, которые влияют на их жизнь в рамках городского пространства.

Таким образом, дети и молодежь имеют возможность получить активную городскую среду развития, в условиях, когда они всегда могут: влиять на принятие решений наряду со взрослыми горожанами (с учетом возрастных особенностей), высказывать свое мнение о городе (в приемлемой форме), активно участвовать в не только в семейной, но и в общественной жизни; чувствовать себя свободно и безопасно на улицах города, проводя время вне дома, встречаться с друзьями и играть, жить в экологически и социально безопасной среде, участвовать в культурных и общественных мероприятиях, быть равными гражданами своего города с доступом к любой услуге (с учетом возрастных особенностей), независимо от этнического происхождения, религии, дохода, пола или инвалидности. В городе, доброжелательном к ребенку, дети, насколько это возможно (но более активно, чем мы привыкли это себе видеть), являются активными участниками важных процессов принятия решений. Их голоса и мнения учитываются, и они могут влиять на основные решения.

Обеспечение возможностей вовлечения детей в процессы проектирования и принятия решений может способствовать развитию способностей детей в отношении повышения осведомленности, критического мышления и коллективного решения проблем. Дети могут стать теми заинтересованными сторонами, включенными в процесс принятия решений, касающихся их благосостояния и развития в рамках городской среды. Органы государственной власти должны взять на себя обеспечение адекватными ресурсами и бюджетными ассигнованиями на нужды проектирования городской среды для детей. Для реализации такой цели необходимо четко установить перечень основных показателей.

Обеспечение дружелюбного отношения детей к городам должно выявлять проблемы, с которыми сталкиваются дети на улицах города, и учитывать их в процессе городского проектирования. Применение принципа партисипативности позволит привлечь детей на местном уровне, для того чтобы понять их потребности, оценить параметры городской среды путем вовлечения детей в оценку значимости тех или иных особенностей и вариантов решения проблем [19].

Организация партисипативного городского проектирования не только оказывает непосредственное влияние на жизнь детей в городе, но также подразумевает выделение 
им активной роли в городском развитии и благополучии. Методы городского проектирования, доброжелательного к детству, должны быть в центре городской повестки дня. Нельзя забывать также про партнерство с детскими организациями, СОНКО и пр., которые могут помочь в успешной реализации партисипативного проектирования [20].

Средства массовой информации могут сыграть решающую связь между детьми и лицами, принимающими ключевые решения. Они могут использоваться в качестве важного инструмента для освещения, общественной актуализации проблем, касающихся условий жизни детей, особенно их здоровья и благополучия. Это обеспечивает укоренение идеи безопасности и защищенности детей в городе в массовом сознании горожан. При содействии масс-медиа могут быть созданы форумы для детей, артикулирующие и агрегирующие их точку зрения на ключевые городские проблемы и особенности организации городской активной среды развития.

В городах, доброжелательных к детям, важную роль играют пешеходные мосты, метрополитены, светофоры, уличные фонари, сигналы, специально обозначенные пешеходные полосы, надлежащая разметка дорог, карты маршрутов и т. д., а также система инклюзивного транспорта. Необходимо обеспечить при этом включение безопасности детей в планы развития городской инфраструктуры. Доступность для детей с ограниченными физическими возможностями является еще одной значимой проблемой организации активной городской среды развития в рамках целого города. Дети должны быть определены как одна из значимых групп пользователей городского пространства и муниципальных услуг населению. Особое значение имеет создание доступных объектов инфраструктуры и сервисов для детей, общественных и игровых пространств и т. д.

Общественная сфера в целом и общественные пространства в частности играют важную роль в обеспечении благополучия детей, безопасности, обучения и всестороннего социального развития [21]. Нехватка парковочных мест, перегруженность дорожного движения, пренебрежение правилами дорожного движения, а также отсутствие необходимого числа пешеходных зон и переходов могут вызвать проблемы в области безопасности, что поведет за собой сокращение возможностей развития для детей. На сегодняшний день создание творческих, инновационных, стимулирующих, доступных и безопасных городских пространств для детей является проблемой, потому что это трудно реализовать де-факто. Нужно достичь взаимопонимания и в итоге создать такое пространство, которое детерминирует развитие активной социальной среды. Преобладающее представление о том, что земля в городе является очень дорогой и, следовательно, уж точно не может быть предоставлена под нужды детей, приводит к нехватке полезного детского пространства в городских районах. Необходимо выявить зоны роста в этом направлении, определить, все ли земли в городе используются по назначению? Например, парки и детские площадки: все ли они в должном состоянии и готовы принять детей? Таким образом, каждому городу как минимум необходим некоторый уровень начального аудита, чтобы оценить уровень удовлетворения детских потребностей. Кроме того, выявление неиспользуемых пространств также может помочь в увеличении земельного фонда открытых площадок для детей. При проектировании таких зон необходимо учитывать базовые вопросы доступа и безопасности.

\section{Заключение и выводы}

Показатели ориентированности городского пространства на детское развитие на сегодняшний день всецело определяются взрослыми, а не детьми. Конечно, нельзя утверждать, что взрослые действуют недобросовестно или желают детям плохого. Но это 
явное выражение патерналистского подхода к детям, который преобладает на сегодняшний день в городском проектировании. Такой патернализм детерминирует широкое распространение убеждений о том, что лишь взрослые имеют исключительное право и обязанность принимать решения за детей и вместо них. Мы оправдываем это мышление лишь отсутствием позитивного практического опыта городского развития в данном направлении.

\section{СПИСОК ЛИТЕРАТУРЫ}

1. Akoff R.L. Creating the corporate future. Plan or be planned for. - New York: Wiley \& Sons, 1981. - 276 p.

2. Arnstein S.N. A ladder of citizen participation // Journal of the American Institute of Planners. - 1969. № 35:4. - P. 216-224.

3. A youth participatory project to address STIs and HIV among homeless youth / M.T. Dang, A. Amos, M. Dangerfield, B. Ford, R. Kern, M. Moon. URL: https://pubmed.ncbi.nlm.nih.gov/29902090/ (дата обращения 11.07.2021).

4. Dayer C. The project of projecting // Journal of Architectural Education. - 2018. - V. 72:1. - P. 2-3. DOI: 10.1080/10464883.2018.1410635.

5. Мороз О. Партиципация как культурная практика.URL: https://postnauka. ru/video/75977 (дата обращения 20.12.2020).

6. Сафонова Л.С. К вопросу о социальном управлении // Ленинградский юридический журнал. URL: https://cyberleninka.ru/article/n/k-voprosu-o-sotsialnom-upravlenii (дата обращения 12.12.2020).

7. Шумкин Е.М. Управленческая деятельность актора, как потенциал конфликта интересов: конвергентный подход // Вестник Пермского университета. Философия. Психология. Социология. URL: https://cyberleninka.ru/article/n/upravlencheskaya-deyatelnost-aktora-kak-potentsial-konflikta-interesovkonvergentnyy-podhod (дата обращения 20.12.2020).

8. Казаева Е. А. Роль партисипативности в системе высшего образования // Педагогическое образование в России. URL: https://cyberleninka.ru/article/n/rol-partisipativnosti-v-sisteme-vysshego-obrazovaniya (дата обращения 11.07.2020).

9. Пясецкая И.Ш. Понятийно-терминологический аппарат исследования проблемы формирования партисипативной культуры у будущих менеджеров гостиничного сервиса // Современная высшая школа: инновационный аспект. URL: https://cyberleninka.ru/article/n/ponyatiyno-terminologicheskiy-apparatissledovaniya-problemy-formirovaniya-partisipativnoy-kultury-u-buduschih-menedzherov (дата обращения 11.07.2020).

10. Современные тенденции креативно-прогностического управления в образовании: монография / Н.Ю. Корнеева, М.В. Кожевников, И.В. Лапчинская, Н.В. Уварина, Г.В. Щагина. - Челябинск: Библиотека А. Миллера, 2019. - 193 с.

11. Деникин А.А. К определению термина «партиципация» в контексте современных художественных практик // Наука телевидения. URL: https:/cyberleninka.ru/article/n/k-opredeleniyu-terminapartitsipatsiya-v-kontekste-sovremennyh-hudozhestvennyh-praktik (дата обращения 11.07.2020).

12. Шкитина Н.С. Верификация концепции эмпатийно-партисипативной подготовки будущего учителя: монография. - Челябинск: Библиотека А. Миллера, 2018. - 144 с.

13. Hilli C. Distance teaching in small rural primary schools: a participatory action research project. URL: https://www.tandfonline.com/doi/full/10.1080/09650792.2018.1526695 (дата обращения 11.07.2020).

14. Njeru D.K. A research project submitted to the school of business, in partial fulfillment of the requirements of the degree of master of business administration (project management option) of Kenyatta University. Diss. Magister. - 2018. - 112 p. URL: https://ir-library.ku.ac.ke/bitstream/handle/123456789/7640/Peter\%20Mathenge.pdf?sequence=1\&isAllowed=y (дата обращения 11.07.2020).

15. Barasa F., Tubey J. Community participation in project planning, management and implementation: building the foundation for sustainable development // International Journal of Current Research. - 2013. - V. 5. - Iss. 02. - P. 398-401.

16. Зверев А.И., Карачков С.М., Алешина Е.В. Социальное проектирование в системе управления городом (на примере Гамбурга, Манчестера, Питтсбурга) // Ученые записки Крымского федерального университета имени В.И. Вернадского. Социология. Педагогика. Психология. URL: https://cyberleninka.ru/article/n/sotsialnoe-proektirovanie-v-sisteme-upravleniya-gorodom-na-primeregamburga-manchestera-pittsburga (дата обращения 03.05.2021).

17. Доклад Конференции Организации Объединенных Наций по населенным пунктам (Хабитат). URL: https://unstats.un.org/unsd/statcom/doc01/2001-2r.pdf (дата обращения 03.05.2021). 
18. Конвенция о правах ребенка (одобрена Генеральной Ассамблеей ООН 20.11.1989) (вступила в силу для CCCP 15.09.1990). URL: http://www.consultant.ru/document/cons_doc_LAW_9959/ (дата обращения 03.05.2021).

19. Алешина Е.В. К вопросу о применении социального проектирования в системе управления учреждениями среднего образования: постановка проблемы в контексте социологии управления // Известия Саратовского университета Новая серия. Социология. Политология. URL: https://cyberleninka.ru/article/n/k-voprosu-o-primenenii-sotsialnogo-proektirovaniya-v-sisteme-

upravleniya-uchrezhdeniyami-srednego-obrazovaniya-postanovka-problemy (дата обращения 03.05.2021).

20. Алешина Е.В. Эффективность руководителя в социальном проектировании системы управления учреждением среднего образования. URL: https:/www.elibrary.ru/item.asp?id=43179051 (дата обращения 03.05.2021).

21. Daniel E., Daniel P.A. Megaprojects as complex adaptive systems: The Hinkley point C case // International Journal of Project Management. 2019. URL: https://doi.org/10.1016/j.ijproman.2019.05.001 (дата обращения 03.05.2021).

Поступила 05.05.2021 г. 
UDC 711.43-053.2

\title{
APPROACHES TO ORGANIZING THE DESIGN OF URBAN DEVELOPMENT ENVIRONMENT: A CITY FOR CHILDREN
}

\author{
Alexey I. Zverev, \\ zverefff@ya.ru \\ Elena V. Aleshina, \\ e-w-a-1@yandex.ru \\ Sergey M. Karachkov, \\ serkar@mail.ru \\ Ural Institute of management, branch of RANEPA, \\ 66, 8 Marta street, Yekaterinburg, 620001, Russia
}

\begin{abstract}
Alexey I. Zverev, Cand. Sc., doctoral student, Russian Presidential Academy of National Economy and Public Administration.
\end{abstract}

Elena V. Aleshina, postgraduate student, Russian Presidential Academy of National Economy and Public Administration.

Sergey M. Karachkov, Cand. Sc., doctoral student, Russian Presidential Academy of National Economy and Public Administration.

The relevance of the article lies in formulation of the problem of analyzing the role of children in the design of a child-oriented urban environment in which they develop and grow. The purpose of the article is to study the methods of inclusion of children in the decision-making process on issues of urban design (as full-fledged participants), during which an active urban development environment is formed. The object of the research is the urban environment as a set of conditions for the life of children. As a subject area, the possibility of applying the concept and methodology of participatory design in the formation of this kind of child-friendly urban environment was chosen. The conclusions reached by the authors relate to the situation surrounding the creation of child-friendly cities, as well as the various consequences associated with the emphasis on the importance of integration, institutionalization and innovation. Integration implies the involvement of children in the development of projects focused on them; institutionalization - the need to create appropriate structures and institutions that meet the needs of children in practice; innovation involves new ways of including children in urban development scenarios as full participants in civil proceedings. In other words, there must be the integration of ideas, actions and knowledge, the institutionalization of positive social experience, the innovation of effective ways to meet the child's needs. The authors also came to the conclusion that the main problem of the environment of modern cities is its unfriendliness in relation to the needs of child development, its low educational and upbringing potential since the environment significantly limits the possibilities of dynamic activity of children.

Key words: Design, participation, social actor, educational potential, child friendly cities.

\section{REFERENCES}

1. Akoff R.L. Creating the corporate future. Plan or be planned for. New York, Wiley \& Sons, 1981. $276 \mathrm{p}$.

2. Arnstein S.N. A ladder of citizen participation. Journal of the American Institute of Planners, 1969, no. 35:4, pp. 216-224.

3. Dang M. T., Amos A., Dangerfield M., Ford B., Kern R., Moon M. A youth participatory project to address STIs and HIV among homeless youth. Available at: https://pubmed.ncbi.nlm.nih.gov/29902090/ (accessed 11 July 2020).

4. Dayer C. The project of projecting. Journal of Architectural Education, 2018, vol. 72:1, pp. 2-3. DOI: 10.1080/10464883.2018.1410635.

5. Moroz O. Partitsipatsiya kak kulturnaya praktika [Participation as a cultural practice]. Available at: https://postnauka.ru/video/75977 (accessed 20 December 2020).

6. Safonova L.S. K voprosu o sotsialnom upravlenii [On the issue of social management]. Leningradskiy yuridicheskiy 
zhurnal. Available at: https://cyberleninka.ru/article/n/k-voprosu-o-sotsialnom-upravlenii (accessed 12 December 2020).

7. Shumkin E.M. Upravlencheskaya deyatelnost aktora, kak potentsial konflikta interesov: konvergentny podkhod [Actor's managerial activity as a potential for a conflict of interest: a convergent approach]. Vestnik Permskogo universiteta. Filosofiya. Psikhologiya. Sotsiologiya. Available at: https://cyberleninka.ru/article/n/upravlencheskaya-deyatelnost-aktora-kak-potentsial-konflikta-interesov-konvergentnyy-podhod (accessed 20 December 2020).

8. Kazaeva E.A. Rol partisipativnosti v sisteme vysshego obrazovaniya [The role of participation in the system of higher education]. Pedagogicheskoe obrazovanie v Rossii. Avalable at: https:// cyberleninka.ru/article/n/rolpartisipativnosti-v-sisteme-vysshego-obrazovaniya (accessed 11 July 2020).

9. Pyasetskaya I.Sh. Ponyatiyno-terminologicheskiy apparat issledovaniya problemy formirovaniya partisipativnoy kultury u budushchikh menedzherov gostinichnogo servisa [Conceptual and terminological apparatus for studying the problem of forming a participatory culture in future managers of hotel service]. Sovremennaya vysshaya shkola: innovatsionny aspect. Avalable at: https://cyberleninka.ru/article/n/ponyatiyno-terminologicheskiy-apparat-issledovaniya-problemy-formirovaniya-partisipativnoy-kultury-u-buduschih-menedzherov (accessed 11 July 2020).

10. Korneeva N.Yu., Kozhevnikov M.V., Lapchinskaya I.V., Uvarina N.V., Shchagina G.V. Sovremennye tendentsii kreativno-prognosticheskogo upravleniya v obrazovanii: monografiya [Modern trends in creative and predictive management in education: monograph]. Chelyabinsk, Biblioteka A. Millera Publ., 2019. 193 p.

11. Denikin A.A. K opredeleniyu termina «partitsipatsiya» v kontekste sovremennykh khudozhestvennykh praktik [Towards the definition of the term «participation» in the context of modern artistic practices]. Nauka televideniya. Avalable at: https://cyberleninka.ru/article/n/k-opredeleniyu-termina-partitsipatsiya-v-kontekste-sovremennyhhudozhestvennyh-praktik (accessed 11 July 2020).

12. Shkitina N.S. Verifikatsiya kontseptsii empatiyno-partisipativnoy podgotovki budushchego uchitelya: monografiya [Verification of the concept of empathic-participatory training of the future teacher: monograph]. Chelyabinsk, Biblioteka A. Millera Publ., 2018. 418 p.

13. Hilli C. Distance teaching in small rural primary schools: a participatory action research project Available at: https://www.tandfonline.com/doi/full/10.1080/09650792.2018.1526695 (accessed 11 July 2020).

14. Njeru D.K. A research project submitted to the school of business, in partial fulfillment of the requirements of the degree of master of business administration (project management option) of Kenyatta University. Diss. Magister. 2018. 112 p. Available at: https://ir-library.ku.ac.ke/bitstream/handle/123456789/7640/Peter\%20Mathenge.pdf?sequence $=1 \&$ isAllowed $=y$ (accessed 11 July 2020).

15. Barasa F., Tubey J. Community participation in project planning, management and implementation: building the foundation for sustainable development. International Journal of Current Research, 2013, vol. 5, Iss. 02, pp. 398401.

16. Zverev A.I., Karachkov S.M., Aleshina E.V. Sotsialnoe proektirovanie v sisteme upravleniya gorodom (na primere Gamburga, Manchestera, Pittsburga) [Social Designing in the City Management System (on the Example of Hamburg, Manchester, Pittsburg]. Uchenye zapiski Krymskogo federalnogo universiteta imeni V.I. Vernadskogo. Sotsiologiya. Pedagogika. Psikhologiya. Available at: https://cyberleninka.ru/article/n/sotsialnoe-proektirovaniev-sisteme-upravleniya-gorodom-na-primere-gamburga-manchestera-pittsburga (accessed 30 May 2021).

17. Doklad Konferentsii Organizatsii Obedinennykh Natsiy po naselennym punktam (Khabitat) [Report of the United Nations Conference on Human Settlements (Habitat)]. Avalable at: https://unstats.un.org/unsd/statcom/doc01/2001-2r.pdf (accessed 30 May 2021).

18. Convention on the Rights of the Child (approved by the UN General Assembly on November 20, 1989) (entered into force for the USSR on September 15, 1990) // URL: available at: http://www.consultant.ru/document/cons_doc_LAW_9959/(accessed 30 May 2021).

19. Aleshina E.V. K voprosu o primenenii sotsialnogo proyektirovaniya v sisteme upravleniya uchrezhdeniyami srednego obrazovaniya: postanovka problemy $\mathrm{v}$ kontekste sotsiologii upravleniya [On the issue of the application of social design in the management system of secondary education institutions: formulation of the problem in the context of the sociology of management]. Izvestiya Saratovskogo universiteta Novaya seriya. Sotsiologiya. Politologiya. Available at: https://cyberleninka.ru/article/n/k-voprosu-o-primenenii-sotsialnogo-proektirovaniyav-sisteme-upravleniya-uchrezhdeniyami-srednego-obrazovaniya-postanovka-problemy (accessed 30 May 2021).

20. Aleshina E.V. Effektivnost rukovoditelya $v$ sotsialnom proyektirovanii sistemy upravleniya uchrezhdeniem srednego obrazovaniya [The effectiveness of a leader in the social design of the management system of a secondary education institution]. Available at: https://www.elibrary.ru/item.asp?id=43179051 (accessed 30 May 2021).

21. Daniel E., Daniel P.A. Megaprojects as complex adaptive systems: the Hinkley point C case. International Journal of Project Management, 2019. Available at: https://doi.org/10.1016/j.ijproman.2019.05.001 (accessed 30 May 2021).

Received: 05 May 2021. 